\title{
Improving Micronutrient Status of Vulnerable Groups in South-East Asia: The SMILING Experience
}

\author{
Frank Wieringa ${ }^{1}\left(\mathbb{D} \cdot\right.$ Nanna $_{\text {Roos }^{2}} \cdot$ Valerie Greffeuille $^{1} \cdot$ Marjoleine Dijkhuizen $^{2} \cdot$ Jacques Berger $^{1}$
}

Published online: 3 January 2019

(c) Springer Science+Business Media, LLC, part of Springer Nature 2019

Anemia and micronutrient deficiencies remain highly prevalent, affecting over 2 billion people worldwide (Kassebaum and Collaborators GBDA 2016). Because micronutrients are implicated in a wide spectrum of biological functions, deficiency causes a wide range health effects. Micronutrient deficiency is implicated in for example increased risk for diarrheal diseases (zinc deficiency), impaired immune function (several micronutrients), delayed cognitive development in infants and children (iodine and iron deficiency), increased child mortality (zinc and vitamin A deficiency), stunting (zinc deficiency) and anemia (several micronutrients) (Black et al. 2013). Hence, micronutrient deficiencies affect the health and development of individuals and thereby, also of societies. For example, it was estimated that malnutrition and micronutrient deficiencies combined cost a lowincome country such as Cambodia over 250 million US\$ annually (Moench-Pfanner et al. 2016).

To enhance the strategies to improve micronutrient status in five South-East Asian countries (Vietnam, Laos, Thailand, Cambodia and Indonesia), the European Union funded, under the FP7 framework, the SMILING project: Sustainable Micronutrient Interventions to controL deficiencies and Improve Nutritional status and General health in Asia (Berger et al. 2013). The overall aim of the SMILING project was to bring together policymakers, researchers and stakeholders in the five Asian countries, to see how current interventions that targeted micronutrient deficiencies could be improved and/or whether new interventions should be introduced.

The SMILING project restricted itself to children $<5$ years of age and to women of reproductive age.

Frank Wieringa

Franck.wieringa@ird.fr

1 Institute of Research for Development (IRD), UMR Nutripass IRD, UM/SupAgro, Montpellier, France

2 Department of Nutrition, Exercise and Sports, University of Copenhagen, Copenhagen, Denmark
Moreover, the project focussed on six micronutrients: vitamin A, iron, zinc, iodine, vitamin B9 (folic acid) and vitamin B12. These micronutrients were regarded the most important micronutrients in a public health context for the region, even though some interventions in the region, such as micronutrient powders for young children, include more micronutrients than just those six. The choice for these micronutrients was partly driven by history, with most interventions in the 1990s and early 2000 focusing on iodine, iron and vitamin A only (Underwood 1998). Hence, it was assumed that for these three micronutrients, data on prevalence of deficiency in the region and impact of interventions could be found. Zinc deficiency was added to the list because the prevalence of deficiency in the region was recently reported to be high (Laillou et al. 2012), and most countries in the region are regarded as at high risk for zinc deficiency. ${ }^{1}$ And folate and vitamin B12 deficiency were added because of their potential negative health impact during pregnancy. However, this is not to disregard the importance of other micronutrient deficiencies in South-East Asia, such as vitamin D or vitamin B1 deficiency, which recently have been shown to be highly prevalent too in South-East Asia (Whitfield et al. 2017; Laillou et al. 2013).

The SMILING project consisted out of two phases. In the first phase, data was collected on global strategies to combat micronutrient deficiencies in children (Campos Ponce et al. 2018) and in women of reproductive age (Dijkhuizen et al. 2018). Also, data was collected on the prevalence of micronutrient deficiencies and interventions targeting micronutrient deficiencies in the five target countries (Roos et al. 2018). To complement these data, food consumption data in the five countries was analysed too (Ferguson et al. 2018), and food consumption tables for the region were updated and extended (Hulshof et al. 2018).

\footnotetext{
${ }^{1}$ Assessment of the risk of zinc deficiency in populations and options for its control. IZINCG technical document \#1. Supplement 2 edn.: International Nutrition Foundation for United Nations University Press; 2004.
} 
This first phase led to a list of potential strategies, both nutrition-specific as nutrition-sensitive, that could be implemented to improve micronutrient status of children and women of reproductive age. As one could expect, the list of potential strategies differed by country, as each country has its own specific context and background. In the second phase of the project, using multiple criteria mapping, the different strategies were evaluated by a wide range of stakeholders. Multi criteria mapping is a technique to assess the suitability, expected impact and acceptability of interventions among stakeholders (Greffeuille et al. 2018). Stakeholders were asked not only to rank interventions on potential impact, but also on feasibility, acceptability and sustainability. Because stakeholders came from all segments of society, different interests and concerns could be made apparent. The main results of the SMILING project were communicated directly to government representatives and key stakeholders from all the participating South-East Asian countries during a regional meeting held in Phnom Phen, Cambodia in April 2014, when preliminary results had just become available. The present supplement to Maternal and Child Health presents the final analyses of outcomes.

To our knowledge, this is the first time such an integrated approach to improve policies around micronutrient deficiency has been executed in South-East Asia. The involvement of national policymakers right from the start of the project was envisioned, aiming to improve not only the acceptability of the outcomes of the project, but also to accelerate the implementation of outcomes. As shown in the following papers, outcomes were not always straightforward or expected. For example, while novel strategies may not be implemented despite documented expected impact, strategies already in place had a tendency to remain, even if lack of impact was proven. The high-dose vitamin A supplementation for women directly after delivery, for example, was introduced, and later retracted by WHO as intervention to improve vitamin A status in infants, ${ }^{2}$ but this policy remains in place in several countries. However, we are convinced that the SMILING project has led to a much greater awareness in the region on the issues surrounding micronutrient deficiencies, and strategies to improve micronutrient status in children and women of reproductive age. The documentation of the problem of micronutrient deficiencies in the region, and how the problem is addressed differently in the five South-East Asian countries, has stimulated policymakers to consider new approaches and solutions. And this has been the greatest achievement of the SMILING project.

\footnotetext{
2 Guideline: Vitamin A supplementation in postpartum women. [http://whqlibdoc.who.int/publications/2011/9789241501774_eng. pdf].
}

\section{References}

Berger, J., Blanchard, G., Ponce, M. C., Chamnan, C., Chea, M., Dijkhuizen, M., Doak, C., Doets, E., Fahmida, U., Ferguson, E., et al. (2013). The SMILING project: A North-South-South collaborative action to prevent micronutrient deficiencies in women and young children in Southeast Asia. Food and Nutrition Bulletin, 34, S133-S139.

Black, R. E., Victora, C. G., Walker, S. P., Bhutta, Z. A., Christian, P., de Onis, M., Ezzati, M., Grantham-McGregor, S., Katz, J., Martorell, R., \& Uauy, R. (2013). Maternal and child undernutrition and overweight in low-income and middle-income countries. Lancet, 382, 427-451.

Campos Ponce, M., Polman, K., Roos, N., Wieringa, F. T., Berger, J., \& Doak, C. M. (2018). What approaches are most effective at addressing micronutrient deficiency in children $0-5$ years? A review of systematic reviews. Maternal and Child Health Journal. https://doi.org/10.1007/s10995-018-2527-9.

Dijkhuizen, M. A., Greffeille, V., Roos, N., Berger, J., \& Wieringa, F. T. (2018). Interventions to improve micronutrient status of women of reproductive age in Southeast Asia: A narrative review on what works, what might work, and what doesn't work. Maternal and Child Health Journal. https://doi.org/10.1007/s1099 5-018-2637-4.

Ferguson, E. L., Watson, L., Berger, J., Chea, M., Chittchang, U., Fahmida, U., Khov, K., Kounnavong, S., Le, B. M., Rojroongwasinkul, N., et al. (2018). Realistic food-based approaches alone may not ensure dietary adequacy for women and young children in South-East Asia. Maternal and Child Health Journal. https:// doi.org/10.1007/s10995-018-2638-3.

Greffeuille, V., Kameli, Y., Chamnan, C., Chea, M., Daream, S., Winichagoon, P., Butryee, C., Le, B. M., Lua, T. T., Muslimatum, S., et al. (2018). Multi-criteria mapping of stakeholders' viewpoints in five southeast Asian countries on strategies to reduce micronutrient deficiencies among children and women of reproductive age: Findings from the SMILING project. Maternal and Child Health Journal. https://doi.org/10.1007/s10995-018-2636-5.

Hulshof, P., Doets, E., Seyha, S., Bunthang, T., Vonglokham, M., Kounnavong, S., Famida, U., Muslimatun, S., Santika, O., Prihatini, S., et al. (2018). Food composition tables in Southeast Asia: The contribution of the SMILING project. Maternal and Child Health Journal. https://doi.org/10.1007/s10995-018-2528-8.

Kassebaum, N. J., \& Collaborators GBDA. (2016). The global burden of anemia. Hematology/Oncology Clinics of North America, 30, 247-308.

Laillou, A., Pham, T. V., Tran, N. T., Le, H. T., Wieringa, F., Rohner, F., Fortin, S., Le, M. B., Tran D. T., Moench-Pfanner, R., \& Berger, J. (2012). Micronutrient deficits are still public health issues among women and young children in Vietnam. PLOS ONE, 7, e34906.

Laillou, A., Wieringa, F., Tran, T. N., Van, P. T., Le, B. M., Fortin, S., Le, T. H., Pfanner, R. M., \& Berger, J. (2013). Hypovitaminosis $\mathrm{D}$ and mild hypocalcaemia are highly prevalent among young Vietnamese children and women and related to low dietary intake. PLOS ONE, 8, e63979.

Moench-Pfanner, R., Silo, S., Laillou, A., Wieringa, F., Hong, R., Hong, R., Poirot, E., \& Bagriansky, J. (2016). The economic burden of malnutrition in pregnant women and children under 5 years of age in Cambodia. Nutrients. https://doi.org/10.3390/ nu8050292.

Roos, N., Ponce, M. C., Doak, C., Dijkhuizen, M. A., Polman, K., Chamnan, C., Khov, K., Chea, C., Prak, S. (2018). Micronutrient status of populations and preventive nutrition interventions in South East Asia. Maternal \& Child Nutrition. https://doi. org/10.1007/s10995-018-2639-2 
Underwood, B. A. (1998). Perspectives from micronutrient malnutrition elimination/eradication programmes. Bulletin of the World Health Organization, 76(Suppl 2), 34-37.

Whitfield, K. C., Smith, G., Chamnan, C., Karakochuk, C. D., Sophonneary, P., Kuong, K., Dijkhuizen, M. A., Hong, R., Berger, J., Green, T. J., \& Wieringa, F. T. (2017). High prevalence of thiamine (vitamin B1) deficiency in early childhood among a nationally representative sample of Cambodian women of childbearing age and their children. PLoS Neglected Tropical Diseases, 11, $\mathrm{e} 0005814$

Publisher's Note Springer Nature remains neutral with regard to jurisdictional claims in published maps and institutional affiliations. 